\title{
La arquitectura del vino en España. Usos en el pasado, valor de comunicación en el presente y previsión de futuro
}

\section{The architecture of wine in Spain. Uses in the past, value of communication in the present and forecast of the future}

\author{
M.Á. Calvo-Andrés \\ Universidad Rey Juan Carlos, Facultad de Ciencias Jurídicas y Sociales, Departamento de Ciencias de la Educación, el Lenguaje, la \\ Cultura y las Artes, Ciencias Histórico-Jurídicas y Humanísticas y Lenguas Modernas, Madrid, España
}

\begin{abstract}
Resumen. El vino ha acompañado al ser humano desde sus orígenes. Desde el primer vino generado de manera accidental, pasando por los lagares rupestres, el refinamiento aportado por las culturas griegas y romanas, pasando por la edad media en la que se deja en manos de los monasterios la custodia de la cultura del vino, la industrialización de los procesos de elaboración con la revolución industrial, a la edad contemporánea con unos años de declive, hasta el resurgir de finales del siglo XX, la arquitectura ha ido cumpliendo distintas funciones en el mundo del vino. La arquitectura ha pasado de contenedor de los procesos de elaboración a convertirse en elemento representativo y generador de imagen de marca de las bodegas, apoyándose el sector vitivinícola en arquitectos de reconocido prestigio para buscar la sinergia entre ambos. La arquitectura del vino ha evolucionado desde la cueva a arquitecturas icónicas impactantes y representativas, capaces de dar visibilidad a las bodegas. La presente investigación pretende un acercamiento mediante el repaso de las fuentes bibliográficas sirviendo como esbozo del estado del arte de la arquitectura del vino en España, poniendo el foco en el presente como factor de comunicación, e intentando hacer una previsión a futuro.
\end{abstract}

\begin{abstract}
The wine has accompanied the human being from its origin. From the first accidentally generated wine, through the cave presses, the refinement provided by the Greek and Roman cultures, passing through the average age in which the custody of the wine culture is left in the hands of the monasteries, industrialization from the processes of elaboration with the industrial revolution, to the contemporary age with years of decline, until the resurgence of the late twentieth century, architecture has been fulfilling various functions in the world of wine. The architecture has gone through the container of the processes of development to become a representative element and generator of brand image of the wineries, supporting the wine sector in prestigious architects to seek synergy between both. The architecture of the wine has evolved from the cave to iconic architectures of impressive and representative aspect, capable of giving visibility to the wineries. This research intends an approach by reviewing the bibliographic sources serving as a sketch of the state of the art of wine architecture in Spain, focusing on the present as a communication factor, and trying to make a future forecast.
\end{abstract}

\section{Introducción}

La historia del vino y la historia de la humanidad han discurrido en paralelo desde sus orígenes. El vino es uno de los productos que primeramente elaboró el ser humano al convertirse en sedentario.

Resulta complicado datar con exactitud cuándo se elaboró el primer vino, sobre todo porque lo que hoy llamamos vino sería muy diferente al vino primigenio que debieron tomar nuestros ancestros, pero se conoce que durante el Neolítico el ser humano cultivó y acopió los excedentes de los alimentos que obtenía. De manera casual o provocada se obtendría el zumo de alimentos acopiados, por aplastamiento de los mismos, llegando en algunos casos a fermentar esos zumos, convirtiéndose en el caso del zumo de las uvas en un vino primitivo

Ese proceso de vinificación básico, se realizaba de un modo natural sin ningún control de las condiciones térmicas a su alrededor, más allá de las que pudieran aportar los lugares donde se producían.

El control de las condiciones térmicas en el proceso de vinificación ha sido a lo largo de la historia un factor clave para la definición de la arquitectura de las bodegas [1].

El proceso de elaboración del vino, además de la necesidad del control de las condiciones térmicas, conlleva unas necesidades físicas que determinan los espacios que los albergan. En primer lugar, se necesita de un recipiente que servirá para acopiar las uvas y donde se extraerá el zumo de la uva (el lagar). Ese recipiente puede ser el mismo donde posteriormente se llevará a cabo el proceso de fermentación, o bien se trasvasará el mosto a otro recipiente distinto.

La fermentación se realiza en dos fases, siendo en la primera en la que se alcanzan altas temperaturas y se genera anhídrido carbónico, lo que hace necesario realizarlo en espacios bien ventilados para que se produzca 
la renovación de oxígeno. En la segunda fase de fermentación se debe dejar reposar el mosto fermentado en un espacio con unas condiciones higrotérmicas constantes y sin alteraciones. Habitualmente se realiza cada fase de la fermentación en un recipiente distinto, por lo que se produce un trasvase entre recipientes. Estos pasos descritos, se corresponden con una simplificación del proceso, además, en función del tipo de vino que se quiera obtener, y de las características que se busquen, pueden ser necesarios realizar distintos, u otros, procesos. Las cuevas naturales han sido durante siglos esos espacios tranquilos y sin alteraciones que son necesarios para que la segunda fermentación se produzca satisfactoriamente, $\mathrm{y}$ en aquellos lugares donde no existían de forma natural, se han realizado de manera artificial excavando la roca.

La adecuación de los espacios para la elaboración y posterior almacenamiento del vino ha creado un vínculo necesario entre el mundo del vino y la arquitectura. Desde ese primer vino elaborado en una cueva hasta la actualidad, las arquitecturas que han servido a los intereses del vino han sido muy distintas, y con muy diferentes fines. Originalmente la arquitectura ha sido una envoltura necesaria para albergar los procesos de elaboración y crianza, con más o menos valor arquitectónico y estético en función de la época y en manos de quien se encontraba la elaboración del vino. Pero desde finales del siglo $\mathrm{XX}$ se ha producido un cambio, pasando la arquitectura a ser un elemento más a tener en cuenta por los elaboradores de vino para valorizar su marca.

\section{Breve repaso de la historia del vino y su arquitectura}

Muchas civilizaciones antiguas se disputan el origen del vino (más allá de aquellos que atribuyen sus orígenes a la intervención de un dios) resultando lo más probable, que se produjese de manera simultánea en varios lugares a orillas del Mediterráneo [2].

El primer vino que se consumió de forma líquida debió elaborarse y contenerse en una cavidad o hueco en la piedra, siendo muy probable que fuese el lugar donde se almacenaban los alimentos en el interior de una cueva.

Ese hueco o cavidad, que en un principio sería el aprovechamiento de un hueco natural, con posterioridad se realizaría de manera primitiva mediante la labra de piedras, dando lugar a los lagares rupestres. Los lagares son los recipientes donde se obtiene el mosto de las uvas por aplastamiento de las mismas, y por extensión se ha designado de igual manera al espacio físico donde se ubican dichos recipientes.

En un primer momento se usaría un mismo recipiente para la extracción del mosto y la fermentación posterior, aunque en seguida se vio la necesidad de separar ambos procesos en dos recipientes distintos. Disponer ambos recipientes contiguos y a distinta altura facilita el trasvase del líquido de un recipiente más alto a otro más bajo por gravedad, siendo un recurso todavía utilizado en la actualidad.

Una de las civilizaciones más importantes y que han dejado muestras de su relación con el vino fue la egipcia. Los lagares egipcios podían ser lugares al descubierto, o bien resguardados en el interior de edificios. Constaban de uno o varios recipientes en piedra o en barro, donde mediante el pisado directo de la uva o por un prensado mecánico se obtenía el mosto.

El pisado directo de la uva para la obtención del mosto es el sistema más simple pero no logra obtener todo el zumo posible del fruto, por lo que se desarrolló el uso de máquinas básicas, las prensas. Las prensas más sencillas consistían en una simple piedra que se haría rodar en el lagar aplastando a su paso las uvas. El salto evolutivo en la obtención del mosto se produjo con la invención de la prensa de palanca o prensa de viga. Este tipo de prensa fue muy utilizada por los romanos, llegando a conocerse como lagar de palanca o romano aquel donde se disponía este tipo de prensa. La prensa de viga consiste en transmitir la carga de un peso que se coloca en un extremo de una gran viga de madera al otro extremo. Este sistema fue el más utilizado hasta la industrialización de la producción agrícola en el siglo XIX.

Aquellos encargados de la elaboración del vino enseguida se dieron cuenta que su proceso era extremadamente delicado y se veía favorecido por unas condiciones de humedad y temperatura constantes, mejorando con la penumbra, el silencio y la ausencia de olores que pudiesen malograrlo. Se hacía necesario disponer de un lugar para que el mosto reposase y se trasformase en vino. El mejor espacio para el reposo del vino es aquel ubicado en un lugar cercano al lagar, sino en el mismo, de manera que se reduzca el trasiego del mosto lo mínimo posible. Las cuevas, bien naturales o creadas artificialmente, son ideales para este propósito, motivo por el que se encuentran muchos de estos lugares de reposo anexionados o excavados junto a montañas; o excavados bajo los lagares intentando replicar las características que de forma natural pueden aportar las cuevas.

La arquitectura del vino desde el Imperio Egipcio hasta el comienzo de la Edad Media no varió en gran medida, únicamente se fue adecuando a las características particulares de las nuevas zonas donde se fue implantando el cultivo de la vid para la elaboración del vino, adoptando los usos arquitectónicos allí donde se elaboraban los vinos, siempre respetando las precauciones anteriormente descritas respecto a las condiciones climatológicas de los espacios de elaboración y crianza.

Durante la Antigua Grecia y el Imperio Romano, los avances que se produjeron en el mundo del vino tuvieron que ver sobre todo con la manera de cultivar las vides, elaborar los vinos y los usos y modos de consumo. La gran aportación del Imperio Romano, aparte de extender el cultivo de las vides a latitudes alejadas del clima mediterráneo, según iban conquistando territorios, fue, la utilización de las cubas de madera para el almacenamiento y transporte del vino, mucho más ligeras y menos frágiles que las ánforas de cerámica. El cambio del material en el que estaban realizados los contenedores del vino, de cerámica a madera, de modo indirecto influyó en la arquitectura de las bodegas, dando lugar a los espacios tan característicos de almacenamiento de las barricas de madera, que todavía hoy se identifican con el mundo del vino.

Con el nacimiento de la Edad Media, heredera de la cultura romana, continúa la expansión del vino por toda Europa gracias en parte al cristianismo, que lleva aparejado su consumo en el sacramento de la eucaristía; y a la evolución del vino en un producto de primera necesidad [3], que aporta alimento, hidratación y un cierto 
grado de protección frente a infecciones gracias a su poder desinfectante.

Los viñedos durante la Edad Media pasan a ser propiedad de los señores feudales, que dejan mayoritariamente en manos de congregaciones religiosas el cultivo de la vid y la elaboración del vino. En Europa prácticamente cada convento importante debía contar con sus propias viñas para elaborar vino [4].

Los conventos y monasterios eran sometidos a saqueos constantemente, lo que llevó a ocultar las cubas que contenían el vino en los sótanos, encontrando en éstos, los lugares perfectos para su ubicación, y que han sido replicados con posterioridad para conseguir ese hábitat adecuado para el reposo y maduración del vino: las bodegas. Por extensión, se han denominado bodegas a los lugares que aglutinan el espacio de elaboración (lagar) y el de crianza o reposo.

Las bodegas, entendidas como los lugares de reposo y crianza del vino, son la mejor solución para la conservación de los vinos, ya que disponen de las condiciones óptimas de temperatura y humedad constantes [5].

Con el descubrimiento de América se continuó la expansión del vino por el Nuevo Mundo, y se reprodujeron las técnicas utilizadas en Europa, así como la guarda y custodia de la elaboración del vino por las órdenes monásticas.

En la Época Moderna surgen dos innovaciones en el mundo vinícola que perduran hasta nuestros días, la generalización de la botella de vidrio y el uso del tapón de corcho para tapar las botellas en lugar de yesos, ceras o lacres.

En el siglo XVII se fundan algunas de las primeras grandes empresas vinícolas de España, mayoritariamente en el sur de Andalucía por la influencia del comercio con las Indias e Inglaterra. Los puertos marítimos en la costa y las estaciones ferroviarias en el interior, se convierten en los núcleos de intercambio de mercancías, y junto con las zonas donde están asentadas las órdenes monásticas se construyen nuevas bodegas para elaborar vinos dirigidos a la exportación y para el consumo local.

Durante la Edad contemporánea se producen a nivel mundial dos cataclismos que cambiaron el rumbo de la viticultura. En el siglo XIX las vides del mundo son atacadas por el hongo Oídio, que tuvo que ser controlado mediante agentes químicos. Pero la gran catástrofe se produce por el ataque a la vid de la mosca áfida, que provoca la enfermedad de la phyllosera. Estas tragedias mermaron las viñas de todo el mundo, pero sirvieron para homogeneizar las legislaciones y certificados a nivel internacional de los países elaboradores y exportadores de vino para velar por las buenas prácticas en el cultivo de la vid y la elaboración del vino.

En el siglo XIX con el desarrollo de una burguesía industrial, se producen avances en los procesos de elaboración del vino buscando una mejora del producto tanto de calidad como de cantidad, pasando de una elaboración prácticamente manual (se continúa usando la prensa de viga) al uso de recursos mecánicos que dan productos más homogéneos. Durante este período las empresas vinícolas tienen un carácter únicamente industrial, quedando relegados los edificios de elaboración y crianza a espacios meramente prácticos, sin la búsqueda de un valor estético, salvo algunas ilustres excepciones como las bodegas modernistas Codorniu, proyectadas por Puig i Cadafalch en 1898 o las bodegas González Byass fundadas en 1835 en Jerez, de entre las cuales está la famosa Real Bodega La Concha, proyectada por el ingeniero francés Gustav Eiffel. En el centro de Europa, principalmente en el valle del Loira en Francia, se estila la tipología arquitectónica del Château. Un Château es un tipo de casa solariega, en algún caso fortificada, rodeada de una hacienda destinada al cultivo y elaboración de vino como sostén económico, que sirve de residencia a una burguesía rural, siendo una arquitectura refinada y cuidada.

Durante el siglo XIX y principios del XX, se generaliza la utilización del acero inoxidable en los elementos para la elaboración y contención del vino, mucho más asépticos y de mayor tamaño que los contenedores de cerámica. Se trata de un período de tiempo en el sector vitivinícola centrado en el aspecto empresarial, relegando la arquitectura a un segundo, sino, tercer plano.

\section{Presente de la arquitectura del vino en España}

No es hasta finales del siglo XX cuando se produce un cambio de paradigma en el mundo del vino debido a un fuerte crecimiento del sector y a una evolución tanto del cuidado de las vides, la viticultura, como de la mejora y modernización de los procesos de obtención de los vinos, de su comercialización e incluso del modo de construir las bodegas, encargadas a arquitectos de reconocido prestigio [6]. Las bodegas pasan a dar importancia a la arquitectura, al entender que puede ser algo más que un simple contenedor del proceso de elaboración del vino.

Las empresas, y entre ellas las vinícolas, intentan mejorar o generar una imagen de marca gracias al uso de una arquitectura proyectada por un arquitecto de relevancia a nivel internacional y reconocido a nivel profesional, de modo que se consiga una sinergia entre arquitectura y vino. Esta utilización de la arquitectura comunica valores y escribe una nueva cultura para el mundo del vino [6].

Aunque la arquitectura se define comúnmente como el arte de proyectar y construir edificios o espacios para el uso del hombre [7], dispone de un aspecto fundamental en su naturaleza que es el impacto psicológico que genera [8]. Gracias a esta capacidad de impactar y transmitir mensajes, la arquitectura durante toda su historia ha estado al servicio del poder creando símbolos de su fuerza [9]. En el mundo empresarial también se da la necesidad de destacar y mostrar su hegemonía entre empresas del mismo sector, y la arquitectura es un recurso comúnmente utilizado para ello.

Por toda la geografía nacional ha aumentado el número de bodegas diseñadas por arquitectos relevantes, nada que ver con las bodegas tradicionales y cooperativas vinícolas de otras épocas. Las empresas vitivinícolas buscan impulsar su cultura empresarial, con un desarrollo singular basado en la creación de imagen de marca, ya que los consumidores compran marcas, aunque las empresas fabrican productos [10]. Para resultar competitivas y atraer a los consumidores/clientes las empresas deben seguir el ejemplo de las grandes empresas multinacionales que actualmente se dedican a fabricar marcas y no productos [11]. 
Ya no se trata únicamente de elaborar vino, sino que la relación entre productor y comprador se ha convertido en la búsqueda de una experiencia más allá del simple consumo. Mientras que los productos tienen consumidores, los servicios tienen clientes [12].

Los consumidores de vino ahora son clientes a los que hay que atraer no únicamente con un buen vino, en la mayoría de los casos muy semejante entre sí a otros muchos vinos, sino que es necesario diferenciarse con una imagen propia, basada en el producto elaborado, pero también en la apreciación de los valores que quiere transmitir la empresa, y es aquí donde la arquitectura de las bodegas puede ayudar a las empresas bodegueras a obtener sus objetivos. La arquitectura actualmente es más una arquitectura de la comunicación que del espacio [13]. Las bodegas piden a los arquitectos que generen la escenografía adecuada para introducir a los visitantes en la enología, y que a la vez se respete la quietud necesaria para la crianza de sus vinos [14].

En gran parte, el enoturismo en auge en España desde finales del siglo $\mathrm{XX}$, es el culpable de esa necesidad de darse a conocer $\mathrm{y}$ atraer al turista interesado en "desplazarse a entornos vinícolas con el propósito de conocer, disfrutar y compartir experiencias en torno a la Cultura del Vino" tal y como definen el enoturismo desde la Asociación Española de Enoturismo (AEE) y han propuesto para su inclusión en el diccionario de la Real Academia Española. El enoturismo ofrece a las bodegas la ocasión para resaltar los valores y atributos de la marca, influyendo en las percepciones de los consumidores y asegurando mayores beneficios [15].

El vino se ha constituido en un sector clave del sistema agroalimentario de los países con tradición vitivinícola que se han abierto al turismo, añadiendo a la actividad propia de elaboración de vino un abanico de actividades e intereses desde la agricultura hasta la distribución, pasando por el marketing, los hábitos de consumo e incluso la arquitectura [16].

España, como primer país en extensión de viñedo del mundo, y con más de cuatro mil bodegas censadas [17], según datos del año 2018, del Observatorio español del mercado del vino (OeMv) está salpicada de bodegas proyectadas por arquitectos que aportan además de su buen hacer, su reconocimiento y prestigio. Frank Gehry proyectó para Bodegas Marqués de Riscal, La Ciudad del Vino en Elciego, tras el éxito cosechado con el museo Guggenheim de Bilbao, y con la misma intención: atraer visitantes y crear una imagen positiva. Norman Foster diseñó la Bodega Portia en la localidad de Gumiel de Izán. Su compañero en los inicios, Richard Rogers, proyectó para la Bodega Protos en Peñafiel una espectacular bodega que ya forma parte de la imagen de la localidad, junto con su castillo. La arquitecta Zaha Hadid hizo una incursión en el mundo vinícola en España, diseñando un stand conmemorativo de los 125 años de las bodegas López de Heredia Viña Tondonia, y que se puede admirar en la propia bodega en la localidad de Haro. También existen ilustres ejemplos de arquitectos patrios que han erigidos hermosas bodegas. Algunos ejemplos, de los muchos existentes, son: Rafael Moneo en la bodega Propiedad de Arínzano entre Logroño y Pamplona, y en la población de Corullón la bodega de los Descendientes de J. Palacios, o Santiago Calatrava para Bodega Ysios en Laguardia.

\section{Conclusiones}

Es evidente que en el devenir de los siglos, el vino ha sido un huésped que ha conocido desde la cueva lúgubre a las casas más nobles egipcias, griegas y romanas; los sótanos de los monasterios europeos, que después se clonaron en el Nuevo Mundo; pasando por los exquisitos Châteaux, o las sencillas y únicamente prácticas cooperativas; hasta los momentos dulces actuales en los que un gran número de elaboradores de vino, entienden que no se trata únicamente de elaborar el mejor vino, sino envolverlo en la mejor arquitectura posible.

Tres son los factores que están marcando el presente de la arquitectura del vino en España, y que al menos a corto plazo también marcarán el futuro del sector. El enoturismo, la imagen de marca y la ecología, estando los tres factores íntimamente relacionados.

Las bodegas están abriéndose mayoritariamente al enoturismo, lo que les proporciona desde el punto de vista económico unos ingresos por las ventas directas en las bodegas, y por las visitas, en caso de que tengan un coste, además de proporcionar la visibilidad y fidelización de los clientes que visitan sus instalaciones.

La imagen de marca para una bodega resulta imprescindible en la actualidad y para el futuro. Conseguir diferenciarse del resto de sus competidores en un sector en el que los productos que compiten entre sí, tienen diferencias muy sutiles, resulta imprescindible para atraer a un consumidor a conocer sus vinos, y a un cliente a que viva la experiencia enoturística en su visita.

Dentro de los valores que se quieren transmitir por una bodega, a parte de su buen hacer, tradición o modernidad, apoyo a la cultura, conciencia social, etcétera, la ecología se está convirtiendo en uno de los más destacados y más valorados por los consumidores.

La tendencia de la sociedad a vigilar y cuidar más el medio ambiente también ha llegado al mundo del vino. Cada vez son más las bodegas que reducen, o incluso eliminan totalmente de sus procesos el uso de productos no ecológicos, desde el cultivo de la vid a la elaboración del vino. Estos cuidados son vistos de manera positiva por los consumidores y aportan ese valor añadido a la marca que puede ser el factor diferenciador para ser elegido frente a la competencia. Pero la ecología también llega a la arquitectura, siendo un requisito cada vez más demandado a los arquitectos. La arquitectura sostenible o ecológica cuida de utilizar materiales respetuosos con el medio ambiente, que los procesos de construcción tengan la menor huella contaminante posible, y que la demanda energética de uso del edificio sea baja o a poder ser nula.

Enoturismo e imagen de marca se apoyan en la arquitectura, lo que a su vez redundará en que sea una bodega más competitiva. Lo que no resulta fácil de dilucidar es sí en el futuro las bodegas recurrirán a bodegas de diseños espectaculares diseñadas por arquitectos de reconocido prestigio, o recurrirán a bodegas proyectadas con unos valores más ecológicos y con un diseño pensado no únicamente en los procesos de elaboración del vino, sino también en los aspectos relacionados con la acogida de visitantes. La evolución de la arquitectura singular proyectada por arquitectos de prestigio en España para las bodegas, tuvo sus momentos álgidos entre finales del siglo XX y principios del siglo XXI, estando en los últimos años estancada, salvo ilustres excepciones como han sido la 
inauguración en 2018 de la bodega de Descendientes de J. Palacios, firmada por el arquitecto navarro Rafael Moneo, o la bodega que está en construcción para la bodega de Perelada, diseñada por el estudio RCR arquitectes, cuya finalización está prevista para el actual año 2019. Precisamente esta última bodega ya se ha proyectado bajo el sistema de certificación de edificios sostenibles LEED (Leadership in Energy \& Environmental Design) [18].

En el futuro, las bodegas contarán con la arquitectura como soporte de su actividad productora de vino, espacio de recepción de visitantes y como apoyo para generar o mejorar su imagen de marca. Las arquitecturas tendrán que cumplir estos tres requisitos dando mayor o menor importancia en base a la estrategia empresarial de las bodegas. De igual modo, los procesos y la arquitectura serán más o menos ecológicos en función de la filosofía de la bodega y del valor que quieran transmitir. Las bodegas invertirán sus recursos económicos en arquitecturas más cuidadosas con el medio ambiente, o no; en arquitectos con mayor renombre y repercusión mediática, o no, en función de sus posibilidades financieras. Pero lo que resulta innegable es que la arquitectura y el vino son compañeros inseparables que maridan perfectamente, y que han dado, y lo seguirán haciendo, maravillosas construcciones.

\section{Referencias}

[1] D. Peris, Arquitectura y Cultura del Vino (2006)

[2] E. Castro, Discurso pronunciado por el Ilmo. Sr. Don Eduardo Castro en su recepción pública en la Academia de Buenas Letras de Granada (2006)

[3] J. Peñín, Historia del vino (2008)
[4] J.M. Caballero, Breviario del vino (2006)

[5] P. García, Lagares y bodegas tradicionales en Castilla y León (2013)

[6] M. Merino, Serbiluz. Arquitectura en el mundo del vino: maridaje de funcionalidad y comunicación. Año 31, $N^{\circ}$ Especial 6 (2015)

[7] A. Perrelló, Las claves de la arquitectura (1994)

[8] D. Sudjic, La arquitectura del poder (2006)

[9] L1. Moix, Arquitectura milagrosa (2010)

[10] N. Klein, No logo. El poder de las marcas (2007)

[11] J. Godiol, Naomí Klein y el fin de las marcas (2002)

[12] J. Costa, La imagen de marca: un fenómeno social (2004)

[13] R. Venturi, D. Brown y S. Izenour, Aprendiendo de las Vegas: el simbolismo de la forma arquitectónica (1977)

[14] J. Marino, VinoTeQ: vino, tecnología equipos, cali$\mathrm{dad}, \mathrm{N}^{\circ} 39$. Bodegueros que demandan arquitectura (2008)

[15] X. Rius, Enoturismo, una herramienta de marketing (2008)

[16] M. Vaquero. RIVAR Vol. $2 \mathrm{~N}^{\circ} 5$. El turismo enológico en Italia: origen y desarrollo (mayo 2015)

[17] OeMv. Memoria de actividades OeMv 2018. Disponible en: https://www.oemv.es/memoria-deactividades-oemv-2018, consultado el 15-03-2019

[18] Vinos y Cavas Perelada. Blog de Perelada. Perelada confía a RCR la construcción de su nueva bodega. Disponible en: http://www.perelada. com/es/blog/perelada-conf \%C3\%ADa-rcr-laconstrucci $\%$ C3\%B3n-de-su-nueva-bodega, consultado el 20-03-2019 